\title{
O USO DA INFORMAÇÃO NA VIGILÂNCIA EPIDEMIOLÓGICA EM UMA UNIDADE BÁSICA DE SÁUDE
}

\author{
Maria Filomena de Gouveia Vilela \\ Doutora em Saúde Coletiva pela Universidade Estadual de Campinas. \\ Professora Doutora da UNICAMP \\ mena@unicamp.br
}

INTRODUÇÃO: Em Campinas, a Vigilância Epidemiológica (VE) foi descentralizada para o nível local, os Centros de Saúde (CS) na década de noventa. Isso permitiu aos CSs acesso rápido e focalizado aos problemas de saúde que acometem a população da área de abrangência. A VE local se utiliza de vários instrumentos e recentemente as ferramentas informatizadas foram incorporadas ao processo de trabalho. OBJETIVO: Avaliar os benefícios e dificuldades na implantação da ferramenta informatizada em um CS, analisando-se dados e informações disponíveis, registrados manualmente nos anos de 2015 e 2016 e os da planilha online de 2017. Método: Estudo de caso descritivo e quantitativo. Os dados foram coletados do Sistema de Vigilância Local (SV2), Fichas de Investigação Epidemiológica (FIE), prontuários e outros, digitados no Microsoft Excel for Windows ${ }^{\circledR}$. A pesquisa foi aprovada pelo Comitê de Ética em Pesquisa da Universidade com parecer ㄲo 2.585.046. RESULTADOS: Os dados do SV2 2015 e 2016 contemplavam informações básicas sobre o paciente e o agravo; em 2017 foram incluídos tratamento e desfecho, porém, detalhes sobre os casos estavam melhor descritos nas FIE. Em todos os anos analisados, os casos relativos, principalmente às Infecções Sexualmente Transmissíveis (IST), foram em sua maioria negativos (em torno de $98 \%$ ); isso se deve provavelmente ao registro sistemático dos exames solicitados no pré-natal; quanto a sífilis houve oscilação entre os anos: $5,5 \%$, $6,2 \%$ e $9,4 \%$ de casos positivos nos três anos respectivamente, em relação ao total de possíveis casos. Evidenciou-se também, falta de informações quanto a abordagem ou tratamento de parceiros sexuais dos casos positivos para ISTs, em especial os casos de sífilis, que em $100 \%$ dos relatos não havia esse registro. CONCLUSÃO: Observou-se algumas facilidades e avanços ao se utilizar a planilha online do SV2, como por exemplo, dados mais acessíveis e com potencial de uso da informação de forma ágil, direcionada às intervenções da VE local. No entanto, persistem dificuldades relacionadas ao processo de 
trabalho, demonstradas pela falta de padronização de rotinas e fluxos, a complexidade dos registros, além da necessidade de responsabilização da equipe de enfermagem para garantir as tarefas cotidianas da vigilância, o que pode ser potencializado com as mudanças já observadas em 2017.

Palavras-chave: Vigilância em Saúde Pública. Vigilância Epidemiológica. Sistemas de Informação. Atenção Primária à Saúde e Saúde Pública. 